\title{
Si la sostenibilidad es la pregunta, ¿puede ser la comunicación una de las respuestas?
}

\author{
If sustainability is the question, \\ could communication be one of the answers?
}

Aitor Ugarte

Europa vive una crisis económica como no se recordaba. Con Grecia, Irlanda y Portugal en cabeza, y con Italia y España a rebufo, el Viejo Continente se levanta cada día con el sobresalto de cómo se comportará el riesgo país o qué nuevas acciones reclamarán el Fondo Monetario Internacional o las agencias de calificación. Esta incertidumbre económica, derivada de los excesos financieros amparados por aquellos que manejan los mercados, está provocando un intenso debate sobre la sostenibilidad del Estado del Bienestar, uno de cuyos pilares es el sistema nacional de salud. Creo no equivocarme al afirmar que esta epidemia europea se vive o se ha vivido, mutatis mutandis, en muchos países latinoamericanos.

La sostenibilidad de los sistemas nacionales de salud, por tanto, se encuentra amenazada. O al menos esa es la opinión mayoritaria. Para conjurar esa amenaza los gestores públicos proponen diferentes estrategias que se pueden resumir en dos grandes tendencias: una que aboga por el cuasi-desmantelamiento y otra que aboga por la reforma. Situándome en esta segunda opción, trataré de apuntar cómo la comunicación puede ayudar a este proyecto reformista. Para ello, antes conviene explicar cuál es mi punto de vista respecto al necesario cambio de los modelos actuales de salud vigentes en la mayoría de los países de la comunidad iberoamericana. (No he dicho en todos por una mezcla culpable de prudencia y cierto desconocimiento). 
Nos hemos acostumbrado a convivir con un modelo de sistema nacional de salud basado en la enfermedad y en el asistencialismo. Es más, cabría calificar algunos modelos como hospitalocentristas. Esta forma de entender la sanidad, además de incurrir en gastos exponenciales y de incentivar indirectamente la derivación del usuario a las abarrotadas listas de diagnóstico de los especialistas, minusvaloran -bien sea inconscientemente- el trabajo preventivo, comunitario, salubrista... Y esto conlleva innumerables consecuencias. Por ejemplo en la realidad nacional que me es mas cercana, España, los jóvenes recién licenciados en Medicina con mejor nota en el examen de acceso a la especialidad, eligen como primeras opciones cirugía plástica (\$), dermatología o diversas vertientes de la cardiología (sobre todo la quirúrgica). Solo los egresados muy vocacionales o los que no han podido acceder a otra especialidad se conforman con medicina de familia y comunitaria, o medicina preventiva y salud publica. Parece claro el desprestigio de estas actividades entre los médicos españoles más jóvenes. Como he dicho, tómese solo como un ejemplo.

Con el modelo arriba descrito, efectivamente, los sistemas nacionales de salud son insostenibles. La cuestión es que nadie dejó escrito en ningún remedo de Biblia o de Corán sanitario que ese sea el único modelo posible. De hecho, no lo es. Hay alternativas.

En esta línea, animo a que nos interroguemos sobre si queremos seguir apostando -y por tanto seguir invirtiendo- en la enfermedad, o bien intentamos mirar el mundo desde el paradigma de la salud. En el primer caso la curación, la asistencia y en último término el hospital tendrán la prioridad, mientras que en el segundo la prevención, la salud pública y lo comunitario tienen la oportunidad de ir adquiriendo protagonismo. Entiendo que esta última estrategia es la más sostenible. Se concreta, muy a grandes rasgos, en poner cada vez más énfasis en la Salud Pública, entendida en un sentido amplio y multidisciplinar: higienismo básico en aquellos lugares más vulnerables, prevención de la enfermedad y promoción de la salud, seguridad de alimentos y aguas, control de vectores de zoonosis, calidad del aire y salud ambiental, prevención del consumo de drogas (alcohol y tabaco incluidos), reducción de riesgos laborales, etc. Sistemas nacionales de salud más enfocados hacia lo preventivo -hacia una mejor prevención, que no comporte un incremento de la medicalización impertinente, como matiza Andreu Segura- conllevarían un auge de la comunicación como valor, herramienta y fundamento del reformado modelo.

Y en ese paradigma preventivo, hay al menos 6 formas de intervenir comunicativamente; de que la comunicación se convierta en una de las respuestas a la incertidumbre sobre la sostenibilidad de los sistemas de salud.

1. En el trabajo con los medios de comunicación. Poniendo las bases y ayudando a que se generen buenas informaciones periodísticas que, como consecuencia mediata y a medio y largo plazo, contribuyan a construir conceptos sociales atinados y lo más consensuados posibles de la salud y la enfermedad.

2. Desde la comunicación interpersonal y grupal del sanitario con los pacientes. Posibilitando y fomentando la relación de confianza, la escucha y la empatía, teniendo en cuenta que internet ha creado un nuevo ciudadano informado sobre su estado de salud/enfermedad' que matiza la tradicional asimetría entre el sanitario y el usuario. 
3. A través del marketing y de la publicidad social sobre salud. Coordinando y orientando los esfuerzos de tantas y tantas campañas con una mayor profesionalidad y rigor científico. La eficacia y la eficiencia de estas campañas se deben medir para discernir lo que funciona de lo que no. Publicaciones como ésta son foros adecuados para compartir aciertos y errores.

4. Consensuando y comunicando socialmente los riesgos. Sostiene Ulrich Beck, y apuntalan otros autores de referencia tal que Anthony Giddens, Zigmunt Bauman, Edgar Morin o Daniel Innerarity, que como sociedad global tenemos el reto de priorizar los riesgos a los que nos enfrentamos. En un mundo tan complejo, globalizado y dominado por la tecnociencia no se puede prever todo, tampoco todo lo que tienen que ver con la salud. La comunicación de los riesgos que asumamos, además de una mejor comunicación de crisis cuando éstas lleguen, nos hará más fuertes como sociedad.

5. Utilizando la comunicación interna como herramienta para el cambio. Todo cambio cuenta con elementos de resistencia, y las reformas en los sistemas de salud no son una excepción. El uso del lenguaje como creador de nuevos significados que sustituyan a los heredados del pasado es un elemento fundamental para prestigiar e introducir el nuevo modelo en las mentes de los gestores, sanitarios y pacientes más refractarios.

6. Ahondando en la comunicacion comunitaria. La comunicación para el desarrollo social enfocada en aspectos de salud ha dado buenos resultados en muchos lugares de Latinoamérica, y esas experiencias deberían ser más conocidas y tenidas en cuenta en otros contextos geográficos. La participación, el empoderamiento y formas de representación distintas a las actuales enlazan de lleno con los mensajes que nos llegan de la primavera árabe y de movimientos como el 15M español.

Me gustaría recalcar que son tan solo apuntes para el diálogo y la discusión, a la que convoco desde ahora mismo a todos los lectores de Revista de Comunicación y Salud. Para expresar sus puntos de vista a través de las Cartas al Editor. 